\title{
LIFE HISTORY OF DISMORPHIA AMPHIONA BEROE (LEPIDOPTERA: PIERIDAE: DISMORPHIINAE) IN PANAMA*
}

\author{
By Annette Aiello \\ Smithsonian Tropical Research Institute \\ P.O. Box 2072, Balboa, Panama
}

Dismorphia is a neotropical genus of butterflies related to the familiar 'sulfurs,' 'whites,' and 'orange-tips' common in temperate regions. They are of unusual interest due to the participation by adults, of certain species, in mimicry complexes. Indeed, Bates' (1862) influential paper on mimicry was based upon this group of butterflies. Unfortunately, little is known of their immature stages or hostplant relations, and only one life history has been described in the genus to date (Young, 1972). The present paper reports on the immature stages and host plant of a second species.

The following observations were made on Dismorphia amphiona beroe (Lucas) (Figure 1), reared from eggs, during 28 April through 4 June 1980 on Barro Colorado Island (BCI), Panama.

On 28 April, during late morning, a female $D$. a. beroe in the BCI Laboratory Clearing, flew along the forest border in search of oviposition sites. Maintaining a distance of $30-60 \mathrm{~cm}$ from the ground, she touched down briefly upon the leaves of virtually every plant in her path, regardless of whether these were ferns, monocots, or dicots. Oviposition took place on one species only: Inga pezzizifera (Leguminosae), present as five plants (each about 1 meter tall) among the second-growth in the north-west corner of the clearing. Three eggs were laid upon the young leaves of this species, one per plant. Similarly, Young (1972) reported Inga pittieri as the foodplant of $D$. virgo (=D. zaela oreas. Vide Lamas (1979) page 21) in Costa Rica. Eggs

The shiny eggs were $1.5 \mathrm{~mm}$ long, and $0.6 \mathrm{~mm}$ wide, were spindleshaped, and had nine longitudinal ribs, and approximately 30 crossribs. Eggs were nearly invisible due to their strong reflection of the surrounding greenery.

Larvae

Hatching occurred during late morning, on 2 April (male) and 3

*Manuscript received by the editor March 13, 1981. 
April (female); the third egg never hatched. Larval stemmata were visible through the chorion several hours before larval emergence. Neither larva was sacrificed, therefore detailed larval descriptions were not made.

Both individuals passed through five larval instars, head capsule widths for which are shown in Table 1. First instars were yellowgreen, but upon feeding, one day after hatching, they took on the same green color of their food plant. As reported by Young (1972), all instars rested on the undersides of leaves along veins exposed by larval feeding (Figure 2), and thus camouflaged, were very difficult to locate. Final instars (Figure 3) fed on older leaves and were a much darker green than were earlier stages.

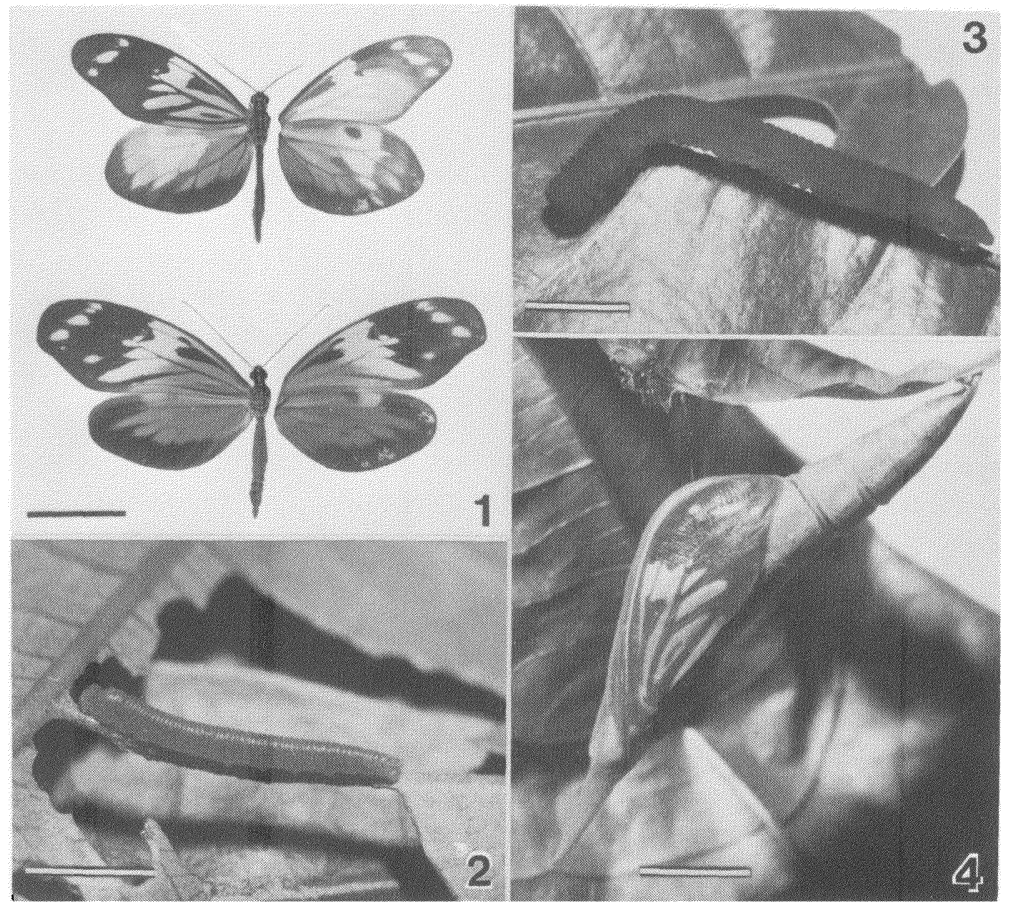

Figures 1-4. Dismorphia amphiona beroe (Rearing lot 80-42). 1. Adult male (above) and female (below), dorsal (left) and ventral (right) views. Scale $=15 \mathrm{~mm}$. 2. Second instar larva (about to molt) resting on underside of leaf, along vein exposed by larval feeding. Scale $=3 \mathrm{~mm}$. 3. Early final instar larva. Scale $=5 \mathrm{~mm}$. 4 . Male pupa several hours before eclosion. Scale $=5 \mathrm{~mm}$. 
Larval body segments were annulate, with four to six annulets each, and covered with numerous short secondary setae that gave a velvety appearance. On each of the nine spiracular segments, the spiracles were situated between annulets 2 and 3 .

First instars had long black setae on the head (5 pairs) and prothorax (2 pairs), and on abdominal segments 9 ( 1 pair) and 10 (2 pairs.). On the prothorax, a third (lowermost) pair of long setae was pale. Later instars lacked either long or black setae. Second through fourth instar heads (Figure 5) had many more setae, and these were raised upon chalazae. While a few were simple slender setae, most were thick, with expanded truncate tips. Final instars had short thick, but pointed setae, also raised upon chalazae. The labrum was emarginate in all instars.

Durations of the immature stages are shown in Table 2.

During the late afternoon and early evening preceding pupation, the fifth instar larva prepared a silk girdle; ecdysis to the pupal took place later the same night.

Table 1. Head capsule widths ( $\mathrm{mm}$ ) for the two reared individuals of Dismorphia amphiona beroe (Rearing lot 80-42).

\begin{tabular}{|c|c|c|c|c|c|}
\hline & & & instar & & \\
\hline & 1 & 2 & 3 & 4 & 5 \\
\hline$\hat{\sigma}$ & 0.38 & 0.63 & 1.08 & 1.67 & 2.50 \\
\hline q & 0.42 & 0.67 & 1.08 & 1.67 & 2.50 \\
\hline
\end{tabular}

\section{Pupae}

The waxy green pupa (Figure 4) was spindle-shaped due to its tapered ends and the curved expansion of the ventral line of its body. The following measurements were made: total length of pupa (29 $\mathrm{mm}$ ); dorso-ventral thickness of pupa at point where girdle crosses dorsum $(6 \mathrm{~mm})$; lengths of prothorax $(2.5 \mathrm{~mm})$, mesothorax $(3.5$ $\mathrm{mm})$, metathorax $(1.5 \mathrm{~mm})$, median cephalic projection $(5 \mathrm{~mm})$, maxillae $(16 \mathrm{~mm})$, prothoracic tibia plus tarsus $(8 \mathrm{~mm})$, mesothoracic tibia plus tarsus $(10 \mathrm{~mm})$, antennae $(15 \mathrm{~mm})$, and mesothoracic wings (12 mm).

The maxillae terminated at a point $1.5 \mathrm{~mm}$ before the wing apices. The metathoracic legs were covered except for their extreme tips. The 
mesothoracic spiracle showed as a slit $1.5 \mathrm{~mm}$ long. The cremaster bore numerous hooked setae.

Pupal waxy greenness persisted until one day before eclosion, at which time the adult wing pattern began to develop (Figure 4).

Pupation lasted eight days for the male and nine days for the female; emergence took place near 9 am on 2 June (male) and 4 June (female).

The two individuals reared, their egg shells, larval head capsules, and pupal skins, are in the author's collection, labelled as Rearing lot 80-42.

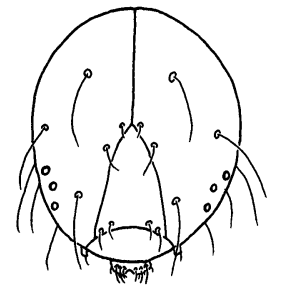

I-1

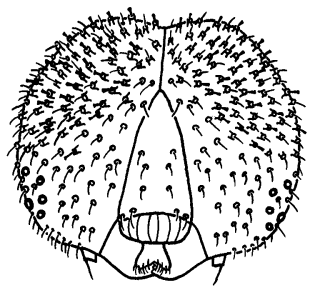

$1-3$

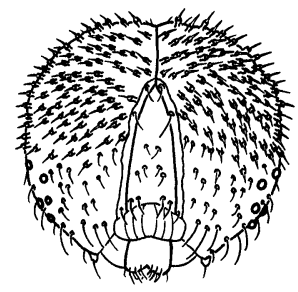

$1-5$

Figure 5. Larval head capsules: first instar (I-1), third instar (I-3), and fifth (final) instar (I-5). Scales $=0.15 \mathrm{~mm}, 0.30 \mathrm{~mm}$, and $0.75 \mathrm{~mm}$ respectively.

Table 2. Number of days spent in each stage by the two individuals of Dismorphia amphiona beroe (Rearing lot 80-42).

\begin{tabular}{|c|c|c|c|c|c|c|c|c|}
\hline & \multirow{3}{*}{ egg } & \multicolumn{5}{|c|}{ instar } & \multirow{3}{*}{ pupa } & \multirow{3}{*}{ total } \\
\hline & & & & & & & & \\
\hline & & 1 & 2 & 3 & 4 & 5 & & \\
\hline$\hat{\sigma}$ & 4 & 4 & 4 & 3 & 5 & 7 & 8 & 35 \\
\hline 우 & 5 & 3 & 4 & 3 & 6 & 7 & 9 & 37 \\
\hline
\end{tabular}

\section{ACKNOWLEDGEMENTS}

I would like to thank the Smithsonian Tropical Research Institute, Panama, for the use of their facilities, Mr. Gordon B. Small for identification of the butterfly, and Dr. Robert Silberglied for helpful suggestions. 


\section{References Cited}

BATES, H. W.

1862. Contributions to an insect fauna of the Amazon Valley. Lepidoptera: Heliconidae. Trans Linnaean Soc London, 23(3): 495-566 + pl. 55-56.

LAMAS, G.

1979. Los Dismorphiinae (Pieridae) de Mexico, America Central y las Antillas. Rev Soc Mex Lepid, 5(1): 3-37.

Young, A.

1972. Notes on the life cycle and natural history of Dismorphia virgo (Lepidoptera: Pieridae: Dismorphiinae) in Costa Rica. Psyche, 79(3): $165-178 .=$. zaela oreas $($ Salvin). Vide Lamas (1979) page 21. 

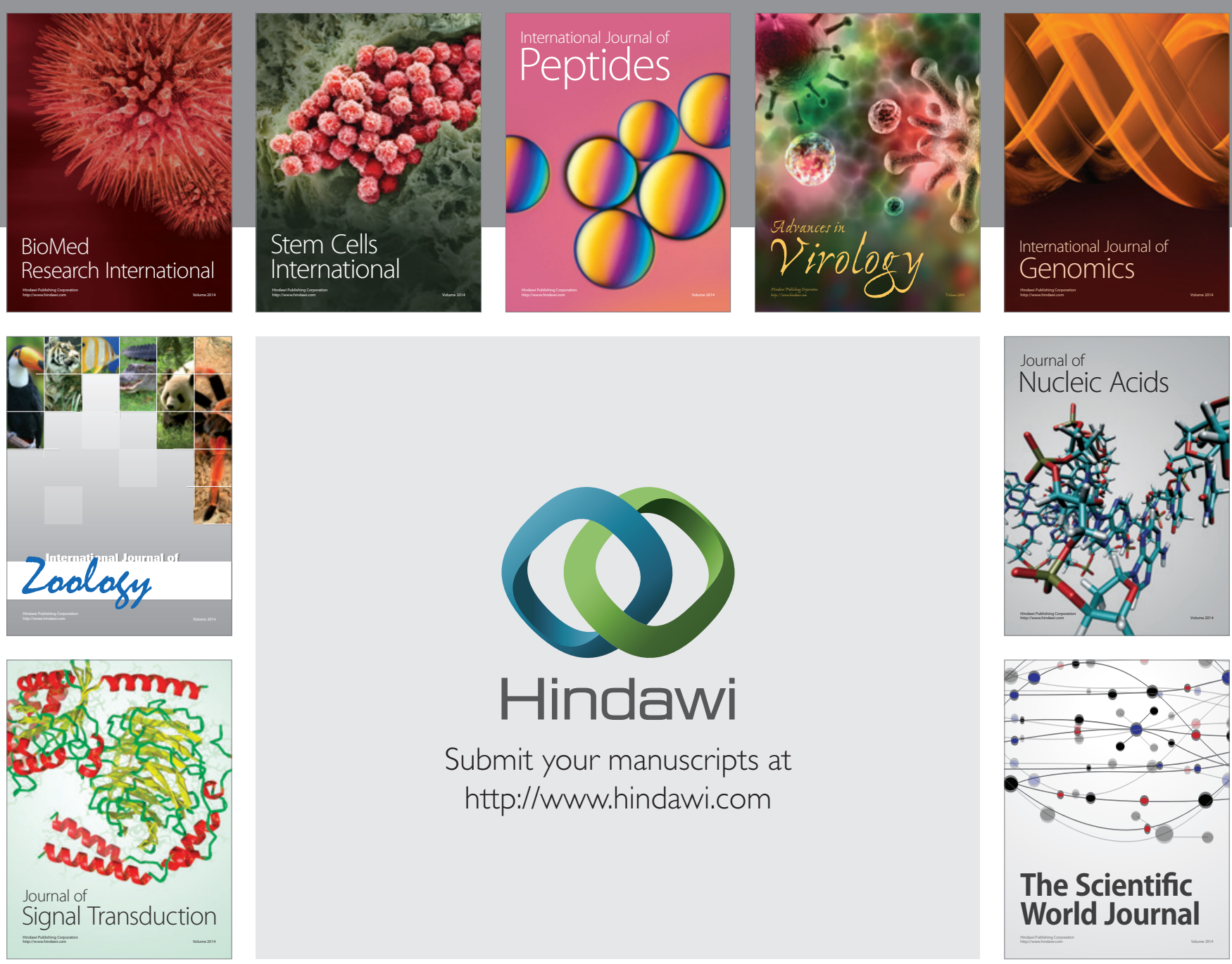

Submit your manuscripts at

http://www.hindawi.com
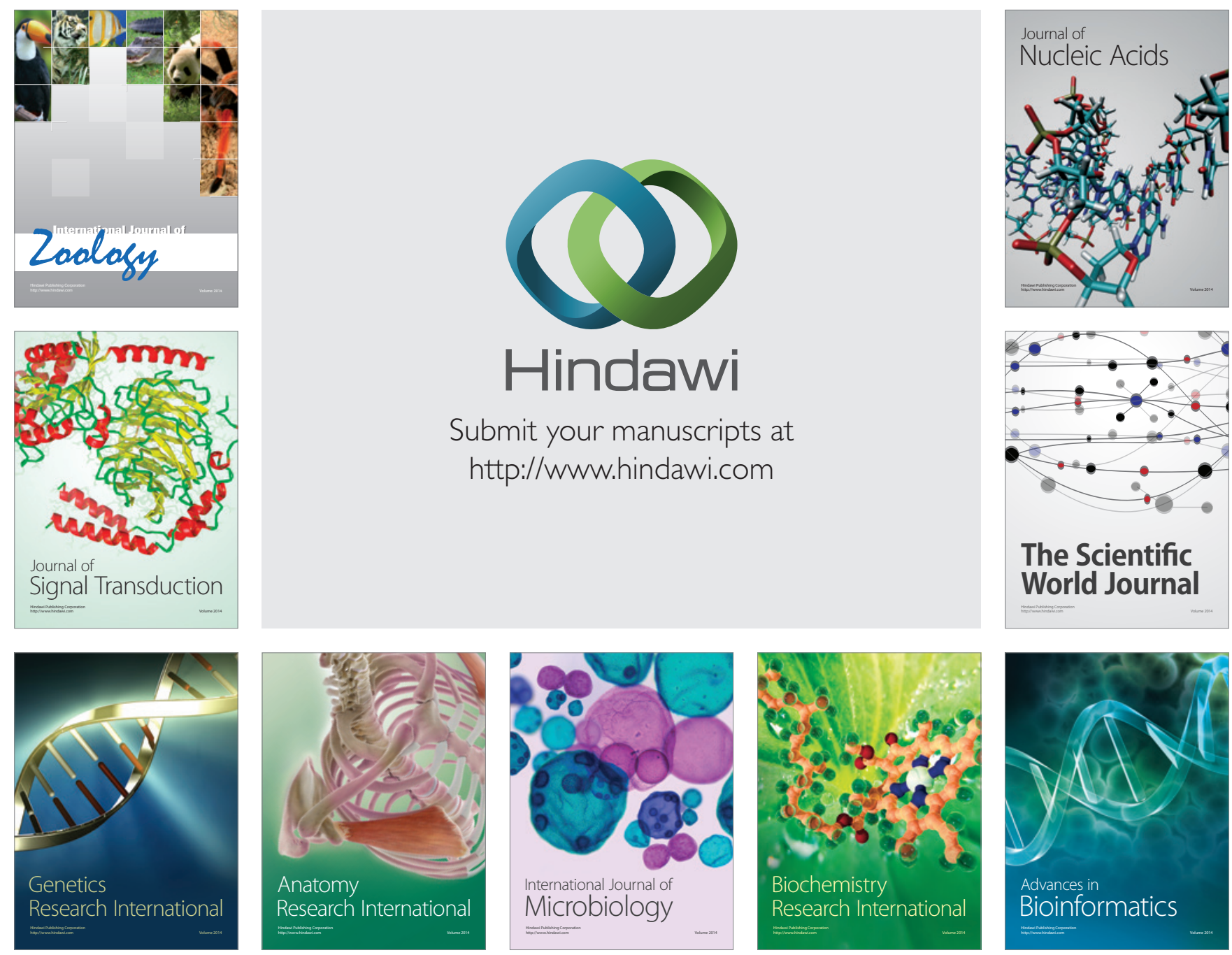

The Scientific World Journal
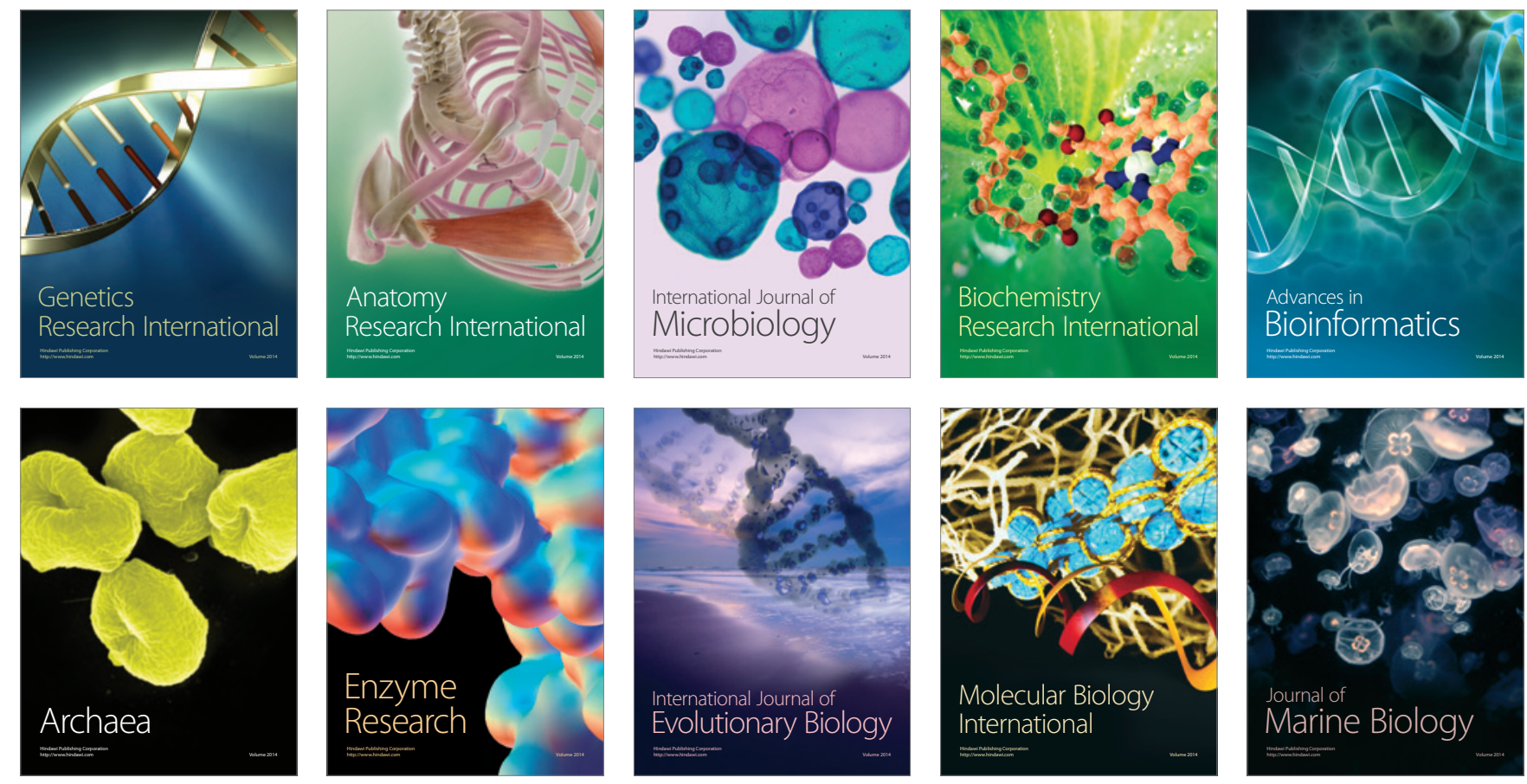